Esta obra está bajo una Licencia Creative Commons Atribución-NoComercial-Compartirlgual 4.0 Internacional

(c) (1) (8) (2)

El Canal de la Ciudad (de Buenos Aires) bajo control gubernamental: en las antípodas del modelo de servicio público Hernán Pajoni

DOI: https://doi.org/10.24215/16696581e204

\title{
EI Canal de la Ciudad (de Buenos Aires) bajo control gubernamental: en las antípodas del modelo de servicio público
}

The Canal de la Ciudad (Buenos Aires) under government control: in the antipodes of the public service model

Hernán Pajoni hpajoni@gmail.com http://orcid.org/0000-0001-8365-1121

Facultad de Ciencias Sociales; Universidad de Buenos Aires/Universidad Católica Argentina (Argentina) 
Hernán Pajoni, El Canal de la Ciudad (de Buenos Aires) bajo control gubernamental: en las antípodas del modelo de servicio público

\section{Resumen}

La Ciudad Autónoma de Buenos Aires no tiene un canal de televisión abierto de carácter estatal. La historia de la radiodifusión en Argentina demuestra que su inexistencia se debe a una ausencia de política cultural y la complicidad del Estado para beneficiar a los operadores privados. El único caso que permite analizar una política cultural en el formato audiovisual generalista es el Canal de la Ciudad. Esta señal de contenidos reproduce un modelo de producción y distribución ajustada a la lógica mercantil de los radiodifusores privados. Con un modelo de gestión gubernamentalizada, con un proceso de producción centralizada y con una programación generalista, esta experiencia demuestra la escasa voluntad de la dirigencia y sus gestores culturales de convertir una herramienta de difusión del estado en una usina de producción cultural diversa, participativa y plural.

Palabras clave: Radiodifusión; servicio público; cultura; política; comunicación.

\section{Abstract}

The Autonomous City of Buenos Aires does not have a state-owned open television channel. The history of broadcasting in Argentina shows that its non-existence is due to a lack of cultural policy and the complicity of the State to benefit private operators. The only case that allows to analyze a cultural policy in the generalaudiovisual format is the City Channel. This content signal reproduces a production and distribution model in line with the commercial logic of private broadcasters. With a model of governmentized management, with a centralized production process and with generalist programming, this experience demonstrates the poor will of the leadership and its cultural managers to turn a state diffusion tool into a diverse, participatory and plural cultural production facility.

Keywords: Broadcasting; public service; culture; politics; Communication 
Hernán Pajoni, El Canal de la Ciudad (de Buenos Aires) bajo control gubernamental: en las antípodas del modelo de servicio público

\section{Introducción acerca del carácter público y su naturaleza}

En una presentación realizada en Colombia en el año 2001 Jesús Martín Barbero presentó una definición sobre los alcances y principios que deben guiar a las televisiones públicas: "Debe ser el escenario del diálogo nacional intercultural (...), debe promover lo universal que no pasa por lo comercial (...), debe ganar el proceso y el flujo propio de las narrativas audiovisuales (...), debe hacer programas de gran impacto, que se conviertan en hechos sociales y ameriten repetición (...), debe ampliar las posibilidades simbólicas de representación, reconocimiento y visibilidad para la construcción de ciudadanía, sociedad civil y democracia (...), debe formar a los televidentes en los ámbitos de la lectura crítica de las imágenes y del control ciudadano sobre los mensajes audiovisuales que se exhiben en toda la televisión (...), debe programarse y producirse por convocatoria pública a través de procesos de asignación de espacios transparentes y participativos, en coherencia con las políticas culturales de comunicación y educación de cada país, y con base en los méritos de los realizadores y productores". Jesús Martín-Barbero (2001) defiende la idea de una TV pública que ofrezca "a todos los públicos un lugar de encuentro, así sea cambiante y precario" como en la reconstrucción de lo público y de allí a una apuesta por el proyecto público de la televisión "que, haciéndose cargo de las nuevas condiciones de producción y oferta, de las innovaciones tecnológicas y las reconfiguraciones de la audiencia", ofrezca los siguientes servicios: (a) reconocimiento y expresión de la diversidad cultural; (b) represente la pluralidad ideológico-política; (c) promueva una información independiente, plural e incluyente de las diferentes situaciones regionales; (d) debido a la fragmentación que introduce el mercado, se hace necesaria un televisión que se dirija al conjunto de ciudadanos de un país, que contrarreste en la medida de lo posible la balcanización de la sociedad nacional.

El modelo de radiodifusión europeo constituido en punto de referencia de la organización no mercantil y no gubernamental de la gestión de los medios masivos de comunicación se basó en la creación de corporaciones públicas; el monopolio de los servicios de radio y televisión; el financiamiento asegurado a través de un canon; la obligación de la cobertura nacional total y de una programación balanceada: "Este modelo europeo de corporación de SPR ha constituido el núcleo desde el cual surgieron los lineamientos básicos en la búsqueda de un modelo latinoamericano" (Linares, 2014: 162). Efectivamente, la doctrina de la Radiodifusión de Servicio Público (RPS) desde su conformación con el diseño de la BBC en Inglaterra, se convirtió en el punto de referencia frente a los modelos mercantiles y privados que nacieron a la luz de la experiencia norteamericana. La RSP se constituye a partir de objetivos político- 
Hernán Pajoni, El Canal de la Ciudad (de Buenos Aires) bajo control gubernamental: en las antípodas del modelo de servicio público

culturales, al servicio de las políticas de Estado para la construcción de modelos de identidad nacional, cohesión social y estabilidad en el ordenamiento político.

Los diseños institucionales y las encrucijadas políticas latinoamericanas pusieron en evidencia las dificultades para el cumplimiento de esos ideales en la gestión de nuestros medios estatales.

Los alcances del modelo de servicio público contempla que el "derecho a la comunicación supone garantizar que el espacio público de la comunicación, donde actúan instituciones como los medios, está abierto realmente a todos las personas y grupos sociales" (Monje, 2006: 4 y 5). Cumplir con este propósito contribuye al mejoramiento de la democratización de los procesos de comunicación masiva porque opera como una "práctica que amplía las posibilidades de participación popular en la toma de decisiones sobre las políticas más globales" (Mastrini y Mestman, 1995: 2). Así, la radiodifusión de servicio público debe ser comprendida como un modo de organización específica -que no es la única y que es parte de una política pública de comunicación- de abordar y dar respuesta a ese interés público, entendido como valor a proteger y promover" (Linares, 2014: 160). Por su parte, si bien Gaetän Tremblay (1988) reconoce la dificultad de hallar una definición única de servicio público, aportó una definición que contiene el núcleo del modelo: "una actividad considerada de interés general por una colectividad y como tal reconocida por el Estado. Dicha actividad de interés general no puede abandonarse a la iniciativa privada y al puro juego de las leyes de mercado, y por tanto el Estado asume directamente su responsabilidad y su control, sometiéndola, si fuera necesario, a un régimen jurídico especial".

La expresión servicio público, para el caso de la radiodifusión, incluye en la experiencia latinoamericana a las emisoras y dispositivos de masas que operan bajo la lógica de servicios sin fines de lucro, "con algún tipo de propiedad pública, no necesariamente estatales -pero que generalmente son de propiedad estatal- y que intentan dar representación plural a la totalidad de los intereses de la sociedad" (Linares, 2014: 161). Focalizados en esta última dimensión, es útil recuperar que la noción incluye "a los medios gestionados directa o indirectamente por el Estado, los principios programáticos que los rigen y los legitiman en el conjunto del sistema de medios de un país (o región) y las normas que estructuran su organización y funcionamiento" (Valente, 2009: 25). Para el caso de latinoamérica, los debates han expuestos la problemática de la gubernamentalización de las emisoras bajo gestión estatal, no solo en los gobiernos militares de facto, sino en los propios gobiernos democráticamente elegidos. 
Hernán Pajoni, El Canal de la Ciudad (de Buenos Aires) bajo control gubernamental: en las antípodas del modelo de servicio público

¿Un modelo latinoamericano?

"Cada país -comenzando por los europeos de vieja tradición en Servicio Público- maneja su propia definición de 'servicio público' en comunicaciones, así que una distinción razonablemente unívoca entre bien y servicio público o entre servicio estatal, gubernamental, oficial, cultural, alternativo, comunitario o de monopolio natural es por el momento difícil de establecer" (Valente, 2005: 73). Por otra parte, "el uso de la expresión public service broadcasting guarda sentidos distintos, siendo aplicado sólo a los medios públicos en algunos países o al conjunto de medios de concesionarios de canales de radio o de TV terrestres, como es el caso de Reino Unido" (2009: 25). En todo caso, es importante retener que la noción incluye "a los medios gestionados directa o indirectamente por el Estado, los principios programáticos que los rigen y los legitiman en el conjunto del sistema de medios de un país (o región) y las normas que estructuran su organización y funcionamiento" (Linares, 2013).

La gestación y consolidación de los dos modelos paradigmáticos de gestión, financiamiento y propuesta cultural en la radiodifusión nacen ya atravesados por una cuestión dilemática no resuelta: el sistema público promueve la calidad cultural y el sistema comercial entretiene en la persecución del lucro. Así el discurso de la calidad se presenta como un imperativo categórico para las televisiones estatales/públicas, mientras que los modelos comerciales legitiman su programación a partir del rendimiento económico de sus emisoras basados en una programación de entretenimiento propio de la comunicación de masas.

Esta diferencia para interpelar a los dos modelos genera debates acerca del modo de regulación en ambos casos. Richeri y Lasagni (2006) destacan dos posiciones: una de ellas promueve la necesidad de establecer "Reglas y obligaciones para todos que incluye a los canales privados a someterse a obligaciones y comportamientos de naturaleza social, política 0 cultural o pedagógica". La condición de empresas productoras de bienes culturales y simbólicos, operando a partir de una concesión otorgada por el Estado debe someterse a un conjunto de regulaciones porque "El entretenimiento no es el estado natural de la televisión, la televisión siempre aunque no se lo proponga es propagadora de ideas, de cultura y de valores, fatalmente"; mientras que otra perspectiva le otorga al sistema comercial la ventaja de juzgar su calidad en términos de eficiencia como empresa. Así ¿La televisión pública debe tener intereses sociales y de servicio, y la privada quedarse solo en la lógica del mercado? Richeri y Lasagni (2006) establecen una serie de obligaciones de las televisiones públicas: responsabilidad respecto de la calidad de su programación, respecto del público destinatario, responsabilidad política sobre un sistema informativo plural, entre otras. 
Hernán Pajoni, El Canal de la Ciudad (de Buenos Aires) bajo control gubernamental: en las antípodas del modelo de servicio público

Para Omar Rincón (2001), "La TV pública debe generar verdades plurales, crear relatos de identidad. Debe preguntarse sobre las experiencias de la gente, la vivencias culturales para la comprensión de la vida cotidiana; sirve para conectar a la gente alrededor de buenas ideas en la lucha por la dignidad, tácticas de visibilización de lo olvidado frente a lo comercial y constructora de conciencia pública". Sostiene que debe ofrecer expresiones que den cuenta de la lucha por las identidades "y el reconocimiento de las comunidades en universos de mixtura cultural". El autor enumera un conjunto de aspiraciones para que la televisión pública cumpla con esos objetivos con propuestas de nuevos lenguajes, formatos, estilos, participación ciudadana y representación de la pluralidad ideológica.

En esta exploración sobre los antecedentes teóricos que guían la definición y de lo público y estatal en el ámbito de la prestación de servicios de comunicación audiovisual, The Broadcasting Research Unit (1989) subrayó los alcances del concepto de calidad y el mandato de las televisiones públicas en el marco de las experiencias británicas. Gutierrez Gea (2000) reunió un este conjunto de visiones y perspectivas que es necesario rescatar para subrayar el aporte para circunscribir el concepto de "calidad", término esquivo como parámetro de referencia para el análisis de la producción televisiva. Un concepto que pese a la búsqueda de certezas no encuentra un sentido que lo cristalice:

1. Una televisión de calidad debe a) "ofrecer una diversidad de opciones, una constante ampliación del tipo de temas y de perspectivas"; b) "buscar constantemente la innovación, no repetir fórmulas, explorar, correr riesgos, sorprender, extender las fronteras, hasta el límite que sea posible de una televisión de calidad". Este enfoque plantea que "una de las pruebas para evaluar la calidad de un programa se tiene cuando ésta captura y mantiene el interés de las personas que tienen un interés ocasional o superficial en un tema, sin sacrificar el rigor requerido para satisfacer su entusiasmo. Esta prueba abarca un amplio número de elementos: el uso del lenguaje, la claridad del argumento, evitar la utilización de un lenguaje especializado, la relevancia de la imagen, entre otros" (The Broadcasting Research Unit, 1989:1-5, en Gutierrez Gea (2000).

2. Ofrecer productos "fascinantes y profundizadores cuyo efecto sería el de hacer que el telespectador sienta que los horizontes se abren y que hay nuevos espacios por descubrir porque su imaginación y la del realizador del programa están trabajando juntas" (Warnock, 1990: 16, en Gutiérrez-Gea, 2000)

En Inglaterra, la norma que regula los contenidos desde 1990 establece que los canales de televisión deben ofrecer una programación con criterios de calidad basados en: 1) programas informativos de alta calidad, nacionales, internacionales y de temas de actualidad, emitidos a intervalos a lo largo del día y en particular a las horas de máxima audiencia; 2) una gama 
Hernán Pajoni, El Canal de la Ciudad (de Buenos Aires) bajo control gubernamental: en las antípodas del modelo de servicio público

adecuada de programas regionales; 3 ) suficiente tiempo para programas religiosos e infantiles; 4) un servicio que atraiga a una amplia variedad de gustos e intereses; 5) suficiente tiempo de programas que sean de alta calidad (Hearst, 1992: 101-102).

De estas definiciones obtenemos la ambigüedad propia que atraviesa tanto discusiones estéticas y éticas como políticas sobre el único término que los reúne, otra vez la calidad. En principio es probable que alcanzar la "calidad" sea un resultado congruente con un diseño de gestión institucionalizado que garantice una administración colegiada, participativa y accesible. Así lo entiende la definición de calidad sostenida por la regulación de la televisión en Suecia: "Una relación entre conjuntos de características (del programa) y el conjunto de valores (de evaluación)". Desde esta perspectiva la calidad no puede reducirse a un único criterio. Así, lo que interesa para una buena política de televisión no es que un criterio de calidad determinado prevalezca sobre todos los demás (elevando las preferencias subjetivas al rango de principio dominante), sino que, por un lado, el sistema en su conjunto considere la búsqueda y la evaluación de la calidad de los programas como objetivos prioritarios; y, por otro lado, se proponga y fomente un amplio espectro de los diversos tipos de excelencia a la que los realizadores pueden aspirar" (Gutierrez Gea, op. cit). Finalmente el trabajo de Gutiérrez Gea aborda el diseño para la calidad definido por la televisión pública de Japón, la Nippon Hoso Kyokai (NHK). Allí se definieron tres líneas programáticas aplicadas a la calidad de la programación, en donde el concepto de "diversidad" adquiere mayor definición y criterios operativos para su ejecución: la diversidad vertical y la diversidad horizontal.

La diversidad vertical contempla la oferta de los diversos géneros televisivos en la programación completa en su conjunto, la que deben cumplimentar: un porcentaje de programación específica para cada uno de los géneros; programas producidos en función de las exigencias de formatos que no caractericen el estándar de la programación generalista de la oferta mainstream; y la distribución equilibrada de la propuesta de programación en todas las bandas horarias.

Para el caso de las corporaciones públicas que gestionan varios canales abiertos de televisión, la diversidad horizontal abarca la administración de los contenidos y el equilibrio en el conjunto de la oferta. En este caso la NHK se propone que en cada uno de los canales que gestiona desarrolle ofertas de contenidos diferentes: programación generalista, educativa y cultural, información y deportes, y entretenimiento y cultura especializada.

En Argentina en particular, con el surgimiento y desarrollo de la radio en la década de 1920 y luego de la televisión casi 4 décadas después respondió a los dos modelos predominantes a nivel mundial en sus orígenes (el servicio público europeo y el sistema comercial norteamericano desarrollado en redes y financiado por la venta de espacios de publicidad). En 
América Latina no se adoptó ninguno de estos modelos de forma orgánica: "Si bien cada país presenta sus particularidades los inicios de la radiodifusión en casi todos los países de la región (con la excepción de Colombia y Chile) predominó un sistema netamente privado de carácter comercial. Paralelamente, se desarrollaron sistema de medios estatales que fueron puestos bajo la órbita de los gobiernos, quienes los usaron mayoritariamente para difundir sus políticas y discursos. Este uso de los medios estatales no contribuyó a fomentar el prestigio de los servicios públicos de radiodifusión en la ciudadanía latinoamericana (Mastrini 2013: 61). La visión de la radiodifusión estatal latinoamericana presenta grandes déficit en relación con las experiencias europeas en la materia a raíz del análisis del desempeño histórico de los medios públicos en América Latina.

\section{El canal de la Ciudad}

Este trabajo se propone evaluar el modelo de gestión, financiamiento y programación de la señal a la luz de las definiciones establecidas en el marco normativo y los objetivos culturales que inspiraron su creación y que siguen vigentes.

\section{Marco normativo y definición institucional}

El capítulo decimosexto de la Constitución de la Ciudad Autónoma de Buenos Aires lleva el título "Comunicación" y consta de un solo artículo de siete líneas de extensión en la impresión original. Allí establece:

"La Ciudad vela para que no sea interferida la pluralidad de emisores y medios de comunicación, sin exclusiones ni discriminación alguna.

Garantiza la libre emisión del pensamiento sin censura previa, por cualquiera de los medios de difusión y comunicación social y el respeto a la ética y el secreto profesional de los periodistas.

El Poder Ejecutivo gestiona los servicios de radiodifusión y teledistribución estatales mediante un ente autárquico garantizando la integración al mismo de representantes del Poder Legislativo, respetando la pluralidad política y la participación consultiva de entidades y personalidades de la cultura y la comunicación social, en la forma que la ley determine.

Los servicios estatales deben garantizar y estimular la participación social."

El decreto № 2428 de 1999 creó la Subsecretaría de Comunicación Social y donde se establece sus alcances y responsabilidades: "Significar, proponer y supervisar las políticas, estrategias y acciones de información, comunicación y difusión de los actos de gobierno y servicios a la comunidad de todas las secretarías y del Poder Ejecutivo. Coordinar las 
Hernán Pajoni, El Canal de la Ciudad (de Buenos Aires) bajo control gubernamental: en las antípodas del modelo de servicio público

actividades de prensa del Gobierno de la Ciudad de Buenos Aires. Coordinar la promoción y difusión radial de actividades relacionadas con el acervo cultural de la ciudad". (Labate, C, 2006)

http://www.buenosaires.gov.ar/areas/leg tecnica/boletines/20000120.htm.

De acuerdo con el glosario de definiciones que plantea la ley de Servicios de Comunicación Audiovisual 26522, en su capítulo II, y respecto del objeto de análisis de este trabajo, el canal de la ciudad está alcanzado por la siguiente definiciones, establecidas en el Art. $4^{\circ}$ de la norma. Es una "señal": "Contenido empaquetado de programas producido para su distribución por medio de servicios de comunicación audiovisual". Asimismo, se trata de una "señal de origen nacional" y por consiguiente es definido por: "Contenido empaquetado de programas producido con la finalidad de ser distribuidos para su difusión mediante vínculo físico, o radioeléctrico terrestre o satelitales abiertos o codificados, que contiene en su programación un mínimo del sesenta por ciento $(60 \%)$ de producción nacional por cada media jornada de programación".

Texto oficial de página web de la señal de contenidos

"Canal de la Ciudad es el canal público de la Ciudad de Buenos Aires. Comenzó a transmitir a partir del 25 de Julio de 2003. Emite las 24 horas del día los siete días de la semana. Es una señal abierta a la comunidad.

La Secretaría de Medios porteña tiene a su cargo la gestión de los canales de comunicación públicos en televisión y radio de la Ciudad de Buenos Aires; además planifica y ejecuta políticas de información de actos de gobierno y servicios a la comunidad, entre otras funciones.

Comenzó a transmitir a partir del 25 de Julio de 2003. En su pantalla aparecen los actores culturales de la Ciudad, muchos de ellos de poca visibilidad mediática, pero de gran interés para los vecinos de Buenos Aires.

La pantalla del Canal de la Ciudad se caracteriza por ofrecer contenidos que no se ven en otros canales y formatos televisivos novedosos.

Parte de su objetivo es convertirse tanto en actor como reflejo de las múltiples manifestaciones audiovisuales que se producen en la Ciudad de Buenos Aires, tanto en literatura como en expresiones estéticas, deportivas, políticas y culturales.

El Canal de la Ciudad busca abrirse al mundo, incorporando e intercambiando programación de primer nivel con las principales metrópolis, trazando de esta manera un nexo entre 
Hernán Pajoni, El Canal de la Ciudad (de Buenos Aires) bajo control gubernamental: en las antípodas del modelo de servicio público

ciudades a nivel internacional."

Fuente: $\underline{\text { https://www.buenosaires.gob.ar/canaldelaciudad }}$

\section{Gubernamentalización, financiamiento publicitario y acceso oneroso}

El pronunciamiento institucional en su página web sobre los alcances y propósitos de las emisiones -transcritas anteriormente- expresa que la programación representa a "Actores culturales de la Ciudad, muchos de ellos de poca visibilidad mediática, pero de gran interés para los vecinos de Buenos Aires", la inexistencia de ámbitos de interacción formales con la producción cultural independiente, y con una gestión centralizada y dependiente del gobierno, tampoco habría garantías institucionales de que así sea.

Como se observó en el cuadro anterior, si bien la señal del gobierno de la ciudad se define como "canal público de la Ciudad de Buenos Aires", no responde a las características constitutivas de lo público, a raíz de su dependencia estructural del poder ejecutivo local. A su vez, se considera "una señal abierta a la comunidad", condición que no se constata en apertura ninguna, es decir, no existe canales formalmente institucionalizados de participación que permitan tal afirmación.

Finalmente "...ofrecer contenidos que no se ven en otros canales y formatos televisivos novedosos", es una afirmación más publicitaria que veraz pues no se advierte la novedad de los formatos televisivos a raíz de la composición de la programación y sus propuestas culturales. La misma objeción se aplica a la última afirmación del texto en la presentación oficial: "Es un canal abierto a la diversidad cultural, a las minorías, a las producciones independientes, al nuevo cine argentino, a las pymes culturales, a los artistas emergentes, al discurso intelectual, al mundo de la ficción y del documental."

Ante la ausencia de reglamentaciones formales y de la inserción de la señal dentro del organigrama de las dependencias administrativas del poder ejecutivo local, surge naturalmente que sus pronunciamientos institucionales está en las antípodas de una gestión independiente y descentralizada que caracterice a una señal pública.

\section{Sobre lo oneroso}

Los criterios de universalidad y gratuidad en el acceso a los contenidos son principios básicos en la definición de un servicio público de radiodifusión, pues el estado debe garantizar y proteger el derecho a la comunicación. 
Hernán Pajoni, El Canal de la Ciudad (de Buenos Aires) bajo control gubernamental: en las antípodas del modelo de servicio público

La condición de señal del denominado "Canal de la Ciudad" lo convierte en un servicio oneroso y como tal discriminatorio respecto de la universalidad en el acceso a los contenidos, porque el acceso está condicionado por la posibilidad del ciudadano de abonar un servicio de televisión paga.

La naturaleza de una señal de contenidos desautoriza cualquier predisposición enunciativa sobre su condición de "abierto a la comunidad", como también incumple flagrantemente los objetivos planteados en la constitución local: "'La Ciudad vela para que no sea interferida la pluralidad de emisores y medios de comunicación, sin exclusiones ni discriminación alguna".

La declaración de principios que expresa el artículo de la Constitución de la Ciudad de Buenos Aires debe expresarse con una reglamentación acorde al espíritu de la ley, como en toda regulación jurídica. Ergo, las adaptaciones administrativas dirigidas al cumplimiento de ese espíritu debería fortalecer operativamente los alcances de la norma o en su defecto licuar o disolver esas disposiciones generales en la espesura de la ambigüedad regulatoria. Esto último suele ser el resultado que más ejemplos reúne en materia de regulación de la radiodifusión.

Porque garantizar "la libre emisión del pensamiento sin censura previa, por cualquiera de los medios de difusión y comunicación social y el respeto a la ética y el secreto profesional de los periodistas", implica necesariamente la implementación de un sistema desgubernamentalizado y con controles colegiados para que tales objetivos no dependan de la buena voluntad de algún gobernante de turno o de su propia percepción acerca de la censura, la diversidad, la calidad y la pluralidad en la pantalla que gestiona.

Asimismo, que para la creación de la subsecretaría de comunicación se disponga que sea esa misma dependencia gubernamental la responsable de "...proponer y supervisar las políticas, estrategias y acciones de información, comunicación y difusión..." expone sin eufemismos la dependencia política, administrativa y centralizada de un medio que se autodefine como público, abierto y respetuoso de la diversidad, como lo indica su texto oficial de presentación.

\section{Quién paga, quién controla, quién programa}

La inexistencia de canales de televisión abiertos, es decir que operen licencias de radiodifusión con uso de espectro radioeléctrico, en las zonas geográficas que concentran mayores recursos económicos y mayor densidad demográfica -especialmente como la Ciudad Autónoma de Buenos Aires- responde a una lógica que caracteriza la historia de las políticas de radiodifusión en la Argentina. Se trata de un modelo que se implementó sobre la base del modelo comercial norteamericano, que culminó con la consolidación del sistema privado, comercial y de 
Hernán Pajoni, El Canal de la Ciudad (de Buenos Aires) bajo control gubernamental: en las antípodas del modelo de servicio público

transmisión en cadenas: "La emisión en red desde mediados de la década del 30 prefiguró un modo desigual y concentrado económico y geográfico en la producción y distribución de la programación de radio: "La televisión, con otra forma de nacimiento y posterior conformación societaria privada y extranjerizada, apenas andando a partir de principios de los 60 ya estableció su carácter privado en cadena, concentrado y desigual, bajo el control patrimonial y cultural de empresas norteamericanas", (Pajoni, 2017). Por otra parte, la relación entre empresas prestadoras de servicios de radiodifusión y el estado como agente regulador fue mayoritariamente resuelto a la luz de la historia de la radiodifusión a favor de los sectores privados, por medio de criterios regulatorios y normativos, y además sobre los acuerdos y presiones que avalaron la inexistencia de prestadores estatales en las zonas de cobertura de prestadores privados. Este criterio de análisis es un hecho flagrante en el caso de la capital de la Argentina, en el que nunca opera ni operó un canal de televisión abierta con control estado local.

La caracterización del modelo de gestión gubernamentalizada para el caso del Canal de la Ciudad es coherente con una larga trayectoria de dependencia política en la gestión de los canales abiertos de los estados provinciales, experiencias donde "el modelo de gestión se organiza a partir de una estructura encolumnada detrás de las decisiones de cada jefe del poder ejecutivo provincial, quien decide la designación o la remoción del director del canal de acuerdo con criterios propios que corresponden a una más de las atribuciones de un jefe de estado" (Pajoni, op.cit), de esta forma la dependencia gubernamental y el financiamiento publicitario pilares de las concepciones mercantiles del sistema de radiodifusión nunca estuvo en consideración de las distintas experiencias políticas de la gestión estatal de estas emisoras.

La dependencia económica de los anunciantes publicitarios y del presupuesto gubernamental destinado a la gestión presenta las dos formas de financiamiento que atentan contra la autonomía de gestión, y que fueron las causas que dieron origen al modelo de radiodifusión de servicio público británico: contra el modelo comercial norteamericano y contra el modelo propagandístico de los autoritarismos europeos.

Así expuestas las limitaciones estructurales / institucionales para que la señal de contenidos del gobierno de la ciudad de Buenos Aires no alcance ni la definición de canal (abierto) y ni la caracterización de público, el siguiente análisis propone contrastar los parámetros de calidad en la programación.

Retomo aquí las definiciones sobre calidad analizadas precedentemente, de acuerdo con las definiciones de la televisión japonesa NHK y The Broadcasting Research Unit, especialmente las que permitan su operativización para facilitar el análisis con estos parámetros:

En Inglaterra, la regulación sobre una programación con criterios de calidad se basan en:

Question, Vol. 1, N. ${ }^{\circ}$ 64, octubre-diciembre 2019. ISSN 1669-6581

Instituto de Investigaciones en Comunicación | Facultad de Periodismo y Comunicación Social | Universidad Nacional de La Plata La Plata | Buenos Aires | Argentina

Página 12 de 17 
Hernán Pajoni, El Canal de la Ciudad (de Buenos Aires) bajo control gubernamental: en las antípodas del modelo de servicio público

- $\quad$ programas informativos de alta calidad, nacionales, internacionales,

- una gama adecuada de programas regionales;

- $\quad$ suficiente tiempo para programas religiosos e infantiles;

La Nippon Hoso Kyokai (NHK) define el cumplimiente del criterio de diversidad cuando se ofrece:

- diversos géneros televisivos en la programación completa en su conjunto

- $\quad$ un porcentaje de programación específica para cada uno de los géneros;

- formatos que no caractericen el estándar de la programación generalista de la oferta mainstream;

- la distribución equilibrada de la propuesta de programación en todas las bandas horarias.

\section{Programación del Canal de la Ciudad}

El análisis de la propuesta de contenidos de la programación de la señal no aporta novedades relevantes sobre sus incongruencias con los modelos públicos/estatales definidos por los modelos precedentemente mencionados como referencia. Son llamativas a su vez las paradojas que resultan de comparar la caracterización oficial que hace de su propuesta programática con los contenidos ofrecidos.

El Canal de la Ciudad no contiene ni programas religiosos ni infantiles. No se acredita la existencia de programas internacionales, y no amerita ni siquiera un análisis exhaustivo sobre la diversidad de géneros y formatos; ni la existencia de problemáticas regionales o de minorías. Bastaría con mencionar, como evidencia para el análisis, que el contenido predominante de la programación lo ocupa el magazine "Hoy nos toca" durante 7 horas diarias de lunes a viernes con 5 ediciones:

- $\quad$ De 7 a 12:30 hs: Hoy nos toca a las 7 / Hoy nos toca a las 9 /Hoy nos toca a las 10.

- $\quad$ De 14 a 15 hs.: Hoy nos toca a la tarde

- $\quad$ De 23 a 23:30 hs.: Hoy nos toca a la noche

El formato consiste en un magazine de variedades: información de actualidad, conductores que tratan distintas secciones temáticas, entrevistas y algunos tratamientos humorísticos sobre la realidad. La lógica del formato se ajusta a las producciones mainstream, de entretenimiento y tratamiento estandarizado de la televisión abierta de explotación privada. 
Hernán Pajoni, El Canal de la Ciudad (de Buenos Aires) bajo control gubernamental: en las antípodas del modelo de servicio público

\begin{tabular}{|c|c|c|c|}
\hline Programa & $\begin{array}{l}\text { Horas por semana } \\
\text { sobre } 85 \text { horas de } \\
\text { programación }\end{array}$ & Formato & Temática \\
\hline Hoy nos toca & 35 horas & $\begin{array}{l}\text { Temas de actualidad } \\
\text { con panelistas }\end{array}$ & $\begin{array}{l}\text { Magazine de } \\
\text { variedades }\end{array}$ \\
\hline Cuatro caras bonitas & $2 \frac{1}{2}$ horas & $\begin{array}{l}\text { Temas de actualidad } \\
\text { con panelistas }\end{array}$ & Variedades \\
\hline $\begin{array}{l}\text { Saturdey. La semana } \\
\text { está perdida }\end{array}$ & 1 hora & $\begin{array}{l}\text { Monólogos, diálogos y } \\
\text { gags }\end{array}$ & Comedia / humorístico \\
\hline Campo de batalla & 30 minutos & Debates literarios & Cultura \\
\hline Toma I & 1 hora & Cine & Cultura \\
\hline Pantagruélico & $1 \frac{1}{2}$ horas & $\begin{array}{l}\text { Gastronomía de } \\
\text { buenos aires }\end{array}$ & Variedades \\
\hline $\begin{array}{l}\text { Buenos Aires en } \\
\text { carrera }\end{array}$ & 30 minutos & Running & Deportes \\
\hline Clásicos del Tasso & $2 \frac{1}{2}$ horas & Recitales & Cultura \\
\hline Muy Muscari & 1 hora & $\begin{array}{l}\text { Entrevistas a figuras } \\
\text { del espectáculo }\end{array}$ & Espectáculos \\
\hline Disfrutemos BA & 1 hora & $\begin{array}{l}\text { Actividades del } \\
\text { gobierno porteño }\end{array}$ & Difusión institucional \\
\hline Musicales Baires & 1 hora & $\begin{array}{l}\text { Coberturas de obras de } \\
\text { teatro y musicales }\end{array}$ & $\begin{array}{l}\text { Difusión institucional y } \\
\text { agenda cultural }\end{array}$ \\
\hline Jam Session & 30 minutos & Entrevistas a músicos & Cultura \\
\hline
\end{tabular}


Hernán Pajoni, El Canal de la Ciudad (de Buenos Aires) bajo control gubernamental: en las antípodas del modelo de servicio público

\begin{tabular}{|l|l|l|l|}
\hline Mandinga Tattoo & 30 minutos & $\begin{array}{l}\text { El mundo de los } \\
\text { tatuajes }\end{array}$ & Variedades \\
\hline Puro Heavy & 30 minutos & Música & Cultura \\
\hline En casa cocina coco & $2 \frac{1}{2}$ horas & Entretenimiento & Cocina \\
\hline Expedición Merino & 30 minutos & Expediciones en zonas & Sobre la vida local \\
\hline Cars TV & 30 minutos & Tendencias del & Mercado automotriz \\
& & mercado del automóvil & \\
\hline
\end{tabular}

De la lectura de los datos surge que de las 85 horas de emisión por semana:

- Los programas culturales, aquellos referidos especialmente a la literatura, la reflexión científica y los espectáculos musicales de la vida cultural porteña, ocupan 5 horas de la programación semanal.

- $\quad$ Los programas de humor, entretenimiento, información general y variedades ocupan 9 horas semanales.

- $\quad$ El deporte está programado durante 30 minutos semanales

- No se registra la existencia de noticieros, mientras que cocina y gastronomía cuenta con 4 horas semanales.

- Los programas destinados a la difusión de la agenda de actividades generadas por el ejecutivo local alcanza las 2 horas semanales.

- $\quad$ Sábados y domingos se repite la programación de los días laborales.

- $\quad$ De las 00:00 hs a las 7 hs. se repite la programación del día anterior.

\section{El Canal de la Ciudad en flagrancia}

Las evidencias son abrumadoras, se diría en caso de un veredicto sobre la condición de "público" de la señal en cuestión:

El canal de la ciudad no construyó sistemas representativos ni colegiados de gestión que permitieran la participación de los sectores locales que dice interpretar.

En ningún caso de análisis alcanza a cumplir ningún parámetro del concepto de "público" como lo establece su texto fundacional, pues ni en sus modelos de gestión, financiación y 
programación promueve aspectos diferenciados de las propuestas de los modelos privados de radiodifusión.

La programación es un caso de flagrancia, pues ninguno de sus contenidos se encuadra en modelos donde la diversidad, la pluralidad y la representación de las problemáticas del conjunto y de sus expresiones minoritarias, así como la exploración de nuevos formatos guíen sus contenidos.

Finalmente, se observa que la exposición de sus alcances y objetivos tanto en la norma como en la difusión institucional evidencia la existencia de un parámetro universalmente reconocido de modelo público, no obstante la operación de la señal está en la práctica absolutamente desprovista de tales principios.

\section{Bibliografía}

Barbero J. M. (2001) "Televisión Pública, Televisión Cultural: entre la Renovación y la Invención", en: Televisión Pública: del consumidor al ciudadano. Omar Rincón, compilador. Convenio Andrés Bello y la Fundación Friedrich Ebert. Bogotá, Colombia. Pp. 48/49.

Labate, C. (2006) "Ciudad Abierta: una mirada desde cerca. Estudio de las políticas de comunicación en la Ciudad de Buenos Aires (2003-2006). Tesina de grado, UBA, 2006.

Linares A. F. (2013) "Servicio Público de Radiodifusión: Reflexión latinoamericana de un concepto dinámico", en: Revista AVATARES de la comunicación y la cultura, № 6, Diciembre de 2013.

Gutiérrez-Gea, Ch. (2000). "Televisión y calidad: perspectivas de investigación y criterios de evaluación", en: $\quad$ Zer $\quad N^{\circ} \quad 9, \quad$ pp. $\quad$ 151-184. http://www.ehu.eus/zer/hemeroteca/pdfs/zer09-06

Mastrini, G., Mestman, M. (1995). “¿Desregulación o rerregulación? De la derrota de las políticas a las políticas de la derrota", en: I Jornadas de Jóvenes Investigadores en Comunicación de Buenos Aires.

Mastrini, G. (2013). "Medios públicos y derecho a la comunicación”, en: Mastrini, G., Bizberge, A., De Charras, D. (Eds.), Las políticas de comunicación en el siglo XXI (pp. 53-74). Buenos Aires: La Crujía.

Monje, D. (2006). "Apuntes para el estudio de Políticas de Radio y TV frente a procesos de integración regional. Caso MERCOSUR", en: UNIrevista. 3, 1-10. Río de Janeiro. 
Pajoni, H. (2017), "Dependientes y mercantilizados: génesis, evolución y actualidad de los canales de televisión de los estados provinciales", en: Revista Question, Vol I, Num 55, julio-septiembre 2017. Pp. 81-99.

http://perio.unlp.edu.ar/ojs/index.php/question/article/view/4238/3553.

Richeri, G. y Lasagni M. C. (2006), "La calidad de la red", en: Televisión y calidad, el debate internacional, cap. 3. La Crujía ediciones, Buenos Aires.

Rincón, O. "Televisión pública: para saber quienes somos, como hemos venido siendo y que queremos ser", en: Televisión pública, del consumidor al ciudadano. Omar Rincón, comp. Ed. Convenio Andrés Bello. Bogotá, 2001.

Tremblay, G. (1988). "La noción de servicio público", en: Revista Telos 14, pp.57-63, Madrid, Fundesco.

Valente, J. (2009). "Concepçoes e abordagens conceituais sobre sistema público de comunicação Social", en: Intervozes - Coletivo Brasil de Comunicação Social (Ed.). Sistemas públicos de comunicação no mundo. Experiencias de doze paises e o caso brasileiro (pp. 25-46). San Pablo: Intervozes/Paulus. 